\title{
Synthesis, microwave spectra, $x$-ray structure, and high-level theoretical calculations for formamidinium formate
}

Cite as: J. Chem. Phys. 150, 094305 (2019); https://doi.org/10.1063/1.5081683

Submitted: 15 November 2018 . Accepted: 30 January 2019 . Published Online: 06 March 2019

Zunwu Zhou, R. Alan Aitken (D), Charlotte Cardinaud, Alexandra M. Z. Slawin, Honghao Wang, Adam M. Daly, Michael H. Palmer, and Stephen C. Kukolich (iD)

ARTICLES YOU MAY BE INTERESTED IN

Modeling vibrational anharmonicity in infrared spectra of high frequency vibrations of polyatomic molecules

The Journal of Chemical Physics 150, 090901 (2019); https://doi.org/10.1063/1.5079626

Well-behaved versus ill-behaved density functionals for single bond dissociation:

Separating success from disaster functional by functional for stretched $\mathrm{H}_{2}$

The Journal of Chemical Physics 150, 094115 (2019); https://doi.org/10.1063/1.5080122

Fourier transform microwave spectroscopy of Criegee intermediates: The conformational behaviour of butyraldehyde oxide

The Journal of Chemical Physics 150, 104301 (2019); https://doi.org/10.1063/1.5088566

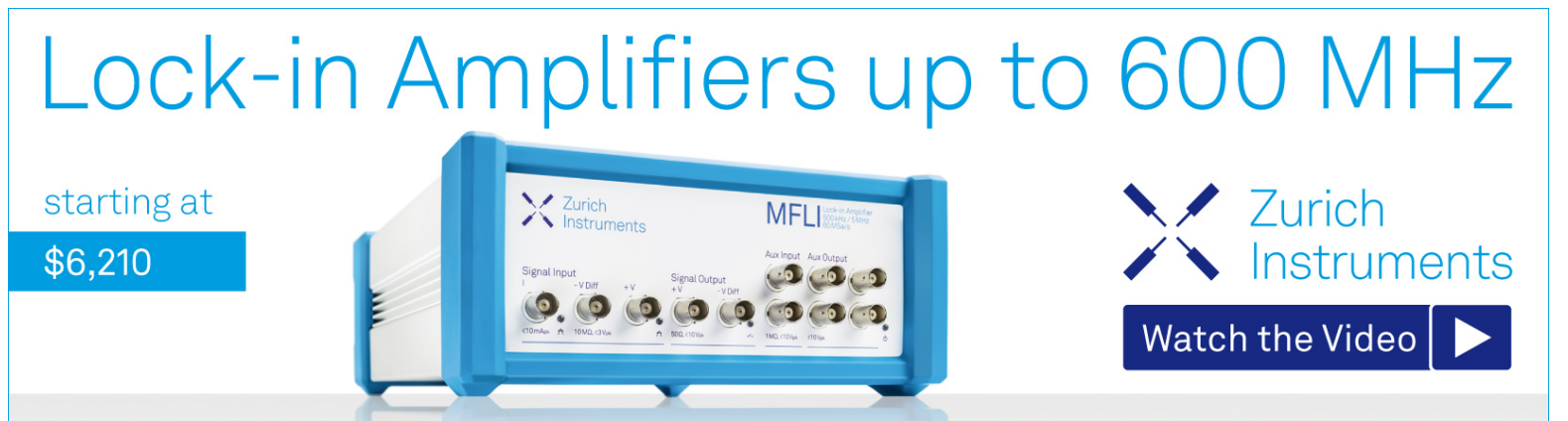

J. Chem. Phys. 150, 094305 (2019); https://doi.org/10.1063/1.5081683 


\title{
Synthesis, microwave spectra, x-ray structure, and high-level theoretical calculations for formamidinium formate
}

\author{
Cite as: J. Chem. Phys. 150, 094305 (2019); doi: 10.1063/1.5081683 \\ Submitted: 15 November 2018 - Accepted: 30 January 2019 • \\ Published Online: 6 March 2019
}

Zunwu Zhou, ${ }^{1}$ R. Alan Aitken, ${ }^{2}$ (D) Charlotte Cardinaud, ${ }^{2}$ Alexandra M. Z. Slawin, ${ }^{2}$ Honghao Wang,

Adam M. Daly, ${ }^{1}$ Michael H. Palmer, ${ }^{3}$ and Stephen G. Kukolich

\section{AFFILIATIONS}

${ }^{1}$ Department of Chemistry and Biochemistry, University of Arizona, Tucson, Arizona 85721, USA

${ }^{2}$ EaStCHEM School of Chemistry, University of St. Andrews, North Haugh, St. Andrews, Fife KY16 9ST, United Kingdom

${ }^{3}$ EaStCHEM School of Chemistry, University of Edinburgh, Joseph Black Building, David Brewster Road,

Edinburgh EH9 3FJ, Scotland, United Kingdom

\begin{abstract}
An efficient synthesis of formamidinium formate is described. The experimental x-ray structure shows both internal and external H-bonding to surrounding molecules. However, in the gas phase, this compound occurs as a doubly hydrogen bonded dimer between formamidine and formic acid. This doubly hydrogen-bonded structure is quite different from the solid state structure. Microwave spectra were measured in the $6-14 \mathrm{GHz}$ range using a pulsed-beam Fourier transform microwave (MW) spectrometer. The two nonequivalent $\mathrm{N}$-atoms exhibit distinct quadrupole coupling. The rotational, centrifugal distortion, and quadrupole coupling constants determined from the spectra have the following values: $A=5880.05(2), B=2148.7710(2), C=1575.23473(13), 1.5 \chi a a(\mathrm{~N} 1)=1.715(3), 0.5(\chi b b-\chi c c)(\mathrm{N} 1)=-1.333(4), 1.5$ $\chi a a(\mathrm{~N} 2)=0.381(2), 0.25(\chi b b-\chi c c)(\mathrm{N} 2)=-0.0324(2)$, and $D_{J}=0.002145(5) \mathrm{MHz}$. The experimental inertial defect, $\Delta=-0.243 \mathrm{amu} \AA^{2}$, is consistent with a planar structure. Accurate and precise rotational constants $(\mathrm{A}, \mathrm{B}$, and $\mathrm{C})$, obtained from the MW measurements, were closely reproduced, within $1 \%-2 \%$ of the measured values, with the M11 DFT theoretical calculations. Detailed comparison of the measured and calculated $\mathrm{A}, \mathrm{B}$, and $\mathrm{C}$ rotational constants confirms the planar doubly hydrogen bonded structure. The calculated nitrogen quadrupole coupling strengths of the monomer are quite different from either of the two nitrogen sites of the dimer. The poor agreement between measured and calculated quadrupole coupling strengths shows that the dimer is not locked in the equilibrium structure but is likely undergoing large amplitude vibrational motion of the hydrogen atoms moving between the $\mathrm{N}$ and $\mathrm{O}$ atoms involved in the hydrogen bonding.
\end{abstract}

Published under license by AIP Publishing. https://doi.org/10.1063/1.5081683

\section{INTRODUCTION}

Formamidinium formate, shown in Fig. 1, is a doubly hydrogen-bonded complex between formamidine and formic acid. The original motivation for this project was to make microwave (MW) measurements on a doubly hydrogen bonded complex with two $\mathrm{N}-\mathrm{H}$ bonds. Many earlier microwave measurements have been made on doubly $\mathrm{H}$-bonded complexes with $\mathrm{O}-\mathrm{H}$ bonds, following the IR work on the formic acid dimer by Havenith et al. ${ }^{1}$ There has been considerable recent interest in doubly hydrogen bonded complexes since they can provide simple models for the hydrogen bonding in DNA base pairs. The DNA base pairs A-T and G-C are held together with $\mathrm{H}$-bonds involving $\mathrm{N}$ atoms. The formamidineformic acid complex (formamidinium formate) provides an opportunity to measure the structure and possibly the dynamics of a doubly $\mathrm{H}$-bonded complex with $\mathrm{N}-\mathrm{H}$ bonds and $\mathrm{C}_{2 \mathrm{v}}(\mathrm{m})$ symmetry. Doubly hydrogen bonded carboxylic acids are not simply static structures but exhibit interesting tunneling dynamics. The simpler carboxylic acid complexes, propiolic acid-formic acid ${ }^{2-4}$ and acetic acid-formic acid, ${ }^{5}$ have been shown to exhibit resolvable concerted proton tunneling splittings in microwave spectra. It appears the tunneling frequencies tend to decrease and the probability of 


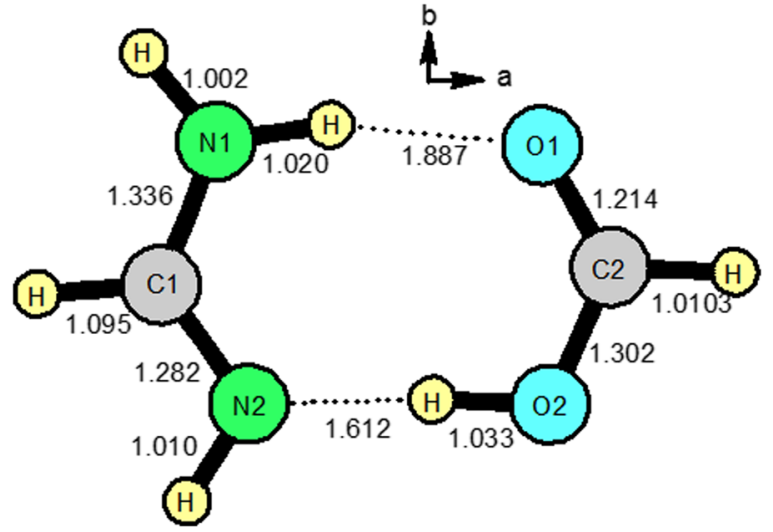

FIG. 1. Structure of the H-bonded complex from the M11 functional with the Def2TZVPPD basis set. The atomic labeling is used throughout this study, including the crystallography and formamidine results. An important feature is that the hydrogenbonding atoms are fairly close to the center of mass of the complex. The long bonds show that this structure is clearly an $\mathrm{H}$-bonded complex and not a pair of ions as in the crystalline state.

observing tunneling splittings in the spectra becomes less as the potential becomes more asymmetric. No tunneling splittings were observed for formic acid-formamide, ${ }^{6}$ 1,2-cyclohexanedioneformic acid, ${ }^{7}$ or cyclopropanecarboxylic acid-formic acid ${ }^{8}$ or the maleimide-formic acid complex. ${ }^{9}$ Tropolone-formic acid has the $\mathrm{C}_{2 \mathrm{v}}(\mathrm{m})$ symmetry but splittings were not observed due to the high barrier. ${ }^{10}$

There are theoretical calculations of double proton transfers in the formamidine formic acid dimer by Kim, Lim, and Kim, ${ }^{11}$ Lim, Lee, and Kim, ${ }^{12}$ Park, Kim, Kim, and Kim, ${ }^{13}$ Radom $^{14}$ et al., and Simperler, Mikenda, and Schwarz. ${ }^{15}$ From the latter two references, it was proposed that the double proton transfer could be asynchronous (non-concerted). The barriers to the proton tunneling were reported to be in the 900 to $1400 \mathrm{~cm}^{-1}$ range, so the tunneling frequencies would be expected in the $1-2 \mathrm{GHz}$ range. This would be expected to produce large splittings of the b-dipole transitions, but splittings would be much smaller or may not be directly observable on the a-dipole transitions. ${ }^{4}$

Studies of these $\mathrm{H}$-bonded systems are readily justified since doubly hydrogen bonded complexes can provide simple models for the hydrogen bonding in DNA base pairs and are of considerable recent interest. ${ }^{16}$ The DNA base pairs, adenine-thiamine $(\mathrm{A}-\mathrm{T})$ and guanine-cytosine $(\mathrm{G}-\mathrm{C})$, are held together with $\mathrm{H}$ bonds involving $\mathrm{N}$ atoms. Arginine, important in molecular recognition and in determining the tertiary structure of proteins, ${ }^{17}$ contains a guanidine group and is also an amidine. The interaction of these with carboxylic acids is of biological importance because enzymic arginine residues may serve as binding sites for carboxylic acids. The amidinium ion has been claimed to be an ideal complement for a carboxylate ion through the formation of a cyclic double hydrogen-bonded structure. ${ }^{18}$ The present microwave (MW) study provides an opportunity for detailed experimental characterization of the species involved. This method provides the most accurate method for determination of gas-phase molecular structures. ${ }^{19}$ The present study of the complex between formamidine and formic acid provides accurate and precise rotational constants, and quadrupole coupling interaction strength at each $\mathrm{N}$-atom. These couplings give information on the electronic charge distribution modified by H-bonding, which were obtained for in the present complex. If dynamic processes, such as proton tunneling, occur in the $\mathrm{kHz}$ to $\mathrm{GHz}$ range, they can often be measured by observing the splittings of lines in the microwave spectrum.

The electron distribution in free formamidine is quite different from the present dimer, as discussed below. Whilst the structure of this fundamental compound is still unknown, a number of its derivatives have found value as acaricides. ${ }^{20}$

The present work provides accurate and precise rotational constants, and quadrupole coupling interaction strengths. The excellent agreement between the measured and calculated rotational constants gives confidence that the calculated structures accurately represent the gas-phase structure of the complex. The gas-phase structure of the formamidinium formate complex is shown in Fig. 1.

\section{EXPERIMENTAL}

\section{A. Synthesis and $x$-ray study}

The first journal report on the preparation of formamidinium formate involves starting from the more readily prepared formamidinium acetate and passing it through the formate form of an ion exchange resin. ${ }^{21}$ Since this was not convenient or amenable to large scale preparation of the compound, we located and optimized a slightly earlier patent report ${ }^{22}$ which involves heating ammonium formate with an excess of trimethyl orthoformate causing reaction according to the following equation:

$$
\begin{aligned}
2 \mathrm{NH}_{4} \mathrm{HCO}_{2}+2 \mathrm{CH}(\mathrm{OMe})_{3} \rightarrow & \mathrm{HC}\left(\mathrm{NH}_{2}\right)_{2} \mathrm{HCO}_{2} \\
& +2 \mathrm{HCO}_{2} \mathrm{Me}+4 \mathrm{MeOH} .
\end{aligned}
$$

Keeping the mixture at $100{ }^{\circ} \mathrm{C}$ with a distillation setup for several hours leads to gradual collection of a mixture of methyl formate (bp $32{ }^{\circ} \mathrm{C}$ ) and methanol $\left(65^{\circ} \mathrm{C}\right)$ as they are formed. When no further distillate is collected, the residual mixture is evaporated under reduced pressure to leave the crude product as a colourless hygroscopic solid. The patent procedure ${ }^{22}$ involves washing this with 1,4dioxane, but in our hands this led to complete dissolution of the product. Instead it was washed briefly with cold diethyl ether and sucked dry on a sintered glass funnel to give pure formamidinium formate as colourless crystals, suitable both for X-ray diffraction and for the microwave studies.

In the synthetic procedure, a mixture of ammonium formate ( $31.5 \mathrm{~g}, 0.5 \mathrm{~mol})$ and trimethyl orthoformate $(117.5 \mathrm{~g}, 1.11 \mathrm{~mol})$ was heated at $100{ }^{\circ} \mathrm{C}$ in a flask setup for distillation. The reaction was continued until no further distillate was collected $(\sim .5-6 \mathrm{~h})$. The distillate, consisting of a mixture of methanol and methyl formate, was discarded, and the reaction mixture was evaporated to dryness under reduced pressure. The resulting colourless solid was washed thoroughly with cold dry diethyl ether and sucked dry on a sintered glass funnel to give the product (12.11 g, $54 \%$ ) as colourless crystals, mp $93-94{ }^{\circ} \mathrm{C}$ (Lit. ${ }^{21} 98-99{ }^{\circ} \mathrm{C}$, lit. ${ }^{22}$ $\left.102-103{ }^{\circ} \mathrm{C}\right) .{ }^{1} \mathrm{H}$ NMR $\left(400 \mathrm{MHz}, \mathrm{CD}_{3} \mathrm{SOCD}_{3}\right) \delta 9.86$ (br s, $\left.4 \mathrm{H}\right)$, $8.43(\mathrm{~s}, 1 \mathrm{H}), 7.84(\mathrm{~s}, 1 \mathrm{H})\left[\right.$ Lit. $^{21} 9.52,8.46,7.81$, lit. $\left.{ }^{22} 8.40,7.84\right] .{ }^{13} \mathrm{C}$ NMR $\left(100 \mathrm{MHz}, \mathrm{CD}_{3} \mathrm{SOCD}_{3}\right) \delta 167.8,158.4$ [Lit. $^{21} 167.6,158.2$ ]. 
Undecoupled ${ }^{13} \mathrm{C} \quad \mathrm{NMR}\left(75 \mathrm{MHz}, \mathrm{CD}_{3} \mathrm{SOCD}_{3}\right) \quad \delta \quad 167.8$ (d, $J=185.3 \mathrm{~Hz}), 158.4(\mathrm{~d}, J=188.0 \mathrm{~Hz})$.

Crystal data for $\mathrm{C}_{2} \mathrm{H}_{6} \mathrm{~N}_{2} \mathrm{O}_{2}, M=90.08 \mathrm{~g} \mathrm{~mol}^{-1}$, colourless prism, crystal dimensions $0.06 \times 0.06 \times 0.06 \mathrm{~mm}$, monoclinic, space group $I 2 / a$ (No. 15), $a=6.78160(12), b=8.67468(15)$, $c=8.02479(16) \AA, \beta=104.0910(19)^{\circ}, V=457.879(15) \AA^{3}, Z=4$, $D_{\text {calc }}=1.307 \mathrm{~g} \mathrm{~cm}^{-3}, T=125 \mathrm{~K}, R=0.0328, R_{w}=0.0847$ for 458 reflections with $I>2 \sigma(I)$ and 38 variables. Data were collected on a Rigaku XtaLAB P200 system using graphite-monochromated Cu Ka radiation $\lambda=1.54184 \AA$ and have been deposited at the Cambridge Crystallographic Data Centre as CCDC 1861266. The data can be obtained free of charge from the Cambridge Crystallographic Data Centre via www.ccdc.cam.ac.uk/getstructures.

\section{B. Microwave measurements and analysis}

Microwave measurements were made on the vapor from the crystalline sample described above, in the $3.7-14.3 \mathrm{GHz}$ range using a Flygare-Balle type pulsed-beam Fourier transform microwave spectrometer described previously at the University of Arizona. ${ }^{23,24}$ The sample was loaded into a glass cell in a nitrogen dry box to minimize its complexation with water molecules in the air. One end of the cell was connected to the pulsed valve of the microwave spectrometer, while the other end was connected to a neon gas passing system purified by a Suppelco OMI-1 purifier from Sigma-Aldrich with a backing pressure of $1 \mathrm{~atm}$ during the length of measurements. In order to produce sufficient vapor pressure while trying to minimize decomposition, the sample along with the pulsed valve was heated to and controlled at about $96^{\circ} \mathrm{C}$. The pressure inside the chamber of the spectrometer was maintained at $10^{-6}$ to $10^{-7}$ Torr using a diffusion pump system. The molecules were then carried by neon gas and pulsed into the chamber through a General Valve pulsed valve. The pulsing rate was controlled at $2 \mathrm{~Hz}$ during the collection of the spectrum. Under these conditions, a 5/1 signal to noise ratio signal could be observed for an a-type $20234-1_{0123}$ (here the notation is $\mathrm{J}_{\mathrm{ka}, \mathrm{kc}}, \mathrm{F} 1, \mathrm{~F}$ to indicate the quantum numbers $\mathrm{J}, \mathrm{K}_{\mathrm{a}}, \mathrm{K}_{\mathrm{c}}, \mathrm{F}_{1}$, and $\mathrm{F}$ ) transition at 7386.7607 MHz in a single pulsed beam cycle.

The computed rotational constants from density functional theory (DFT) and Møller-Plesset second-order perturbation theory (MP2) calculations described below were used in the SPCAT program contained in Pickett's program suite to predict the rotational transitions in the $3.7-14.3 \mathrm{GHz}$ range. ${ }^{25}$ Measured microwave transitions and the deviations from the calculated values for the normal isotopologue of formamidine formate are shown in Table I. 34 experimentally measured a-type transitions are listed in Table I and were entered into the SPFIT program in Pickett's program suite to obtain fitted rotational constants, centrifugal distortion constants, and nuclear quadrupole coupling constants. Observed transitions are assigned using the quantum numbers $\left|J K_{a} K_{c} F_{1} F\right|$. These quantum numbers arise from the angular momentum coupling scheme $\mathrm{I}_{\mathrm{N} 1}+\mathrm{J}=\mathrm{F}_{1}$ and $\mathrm{F}_{1}+\mathrm{I}_{\mathrm{N} 2}=\mathrm{F}$. The b-type transitions are either too weak to observe or substantially moved by the possible tunneling effects.

The best fit experimental molecular constants are listed in Table II, along with calculated parameters. The best calculated rotational constants agree with experimental values within $1 \%$. The calculated a-axis dipole moment is clearly the dominant value, and only a-dipole transitions were observed. We take this
TABLE I. Measured microwave transitions and the deviations from the calculated values for the normal isotopologue of formamidine formate. All values are shown in $\mathrm{MHz}$. Measured transitions $\left(v_{\mathrm{obs}}\right)(\mathrm{MHz})$ and deviations of the best-fit calculated frequencies $\left(v_{0-c}\right)(\mathrm{MHz})$.

\begin{tabular}{|c|c|c|c|c|c|c|c|c|c|c|c|}
\hline \multicolumn{10}{|c|}{ Quantum number assignments } & \multicolumn{2}{|c|}{ Formamidine formate } \\
\hline & $\mathrm{K}_{\mathrm{a}}^{\prime}$ & $\mathrm{K}_{\mathrm{c}}^{\prime}$ & $\mathrm{F}_{1}^{\prime}$ & & & $\mathrm{K}_{\mathrm{a}}^{\prime \prime}$ & $\mathrm{K}_{\mathrm{c}}^{\prime}$ & $\mathrm{F}_{1}^{\prime}$ & $\mathrm{F}^{\prime \prime}$ & $v_{\mathrm{obs}}$ & $v_{\mathrm{o}-\mathrm{c}}$ \\
\hline 1 & 0 & 1 & 0 & 1 & 0 & 0 & 0 & 1 & 2 & 3723.351 & -0.004 \\
\hline 1 & 0 & 1 & 2 & 2 & 0 & 0 & 0 & 1 & 1 & 3723.793 & 0.008 \\
\hline 1 & 0 & 1 & 2 & 3 & 0 & 0 & 0 & 1 & 2 & 3724.111 & 0.131 \\
\hline 1 & 0 & 1 & 2 & 1 & 0 & 0 & 0 & 1 & 0 & 3724.133 & 0.151 \\
\hline 2 & 1 & 2 & 3 & 3 & 1 & 1 & 1 & 2 & 2 & 6873.950 & -0.059 \\
\hline 2 & 1 & 2 & 3 & 4 & 1 & 1 & 1 & 2 & 3 & 6874.328 & 0.009 \\
\hline 2 & 1 & 2 & 2 & 3 & 1 & 1 & 1 & 1 & 2 & 6874.616 & -0.024 \\
\hline 2 & 1 & 2 & 2 & 1 & 1 & 1 & 1 & 1 & 1 & 6874.916 & -0.001 \\
\hline 2 & 0 & 2 & 3 & 3 & 1 & 0 & 1 & 2 & 2 & 7386.614 & -0.098 \\
\hline 2 & 0 & 2 & 3 & 4 & 1 & 0 & 1 & 2 & 3 & 7386.761 & 0.007 \\
\hline 2 & 0 & 2 & 1 & 2 & 1 & 0 & 1 & 0 & 1 & 7387.057 & -0.018 \\
\hline 2 & 0 & 2 & 2 & 2 & 1 & 0 & 1 & 2 & 2 & 7387.257 & -0.080 \\
\hline 2 & 0 & 2 & 1 & 2 & 1 & 0 & 1 & 1 & 2 & 7387.069 & -0.097 \\
\hline 2 & 0 & 2 & 2 & 3 & 1 & 0 & 1 & 1 & 2 & 7387.832 & 0.020 \\
\hline 2 & 1 & 1 & 2 & 3 & 1 & 1 & 0 & 1 & 2 & 8021.730 & -0.066 \\
\hline 2 & 1 & 1 & 3 & 3 & 1 & 1 & 0 & 2 & 2 & 8021.292 & 0.093 \\
\hline 2 & 1 & 1 & 3 & 4 & 1 & 1 & 0 & 2 & 3 & 8021.574 & 0.078 \\
\hline 2 & 1 & 1 & 2 & 1 & 1 & 1 & 0 & 1 & 1 & 8021.983 & -0.029 \\
\hline 3 & 0 & 3 & 2 & 3 & 2 & 0 & 2 & 2 & 3 & 10931.084 & 0.035 \\
\hline 3 & 0 & 3 & 2 & 1 & 2 & 0 & 2 & 2 & 1 & 10931.112 & 0.010 \\
\hline 3 & 0 & 3 & 4 & 5 & 2 & 0 & 2 & 3 & 4 & 10931.739 & 0.144 \\
\hline 3 & 0 & 3 & 3 & 2 & 2 & 0 & 2 & 3 & 3 & 10932.393 & 0.001 \\
\hline 3 & 1 & 3 & 2 & 2 & 2 & 1 & 2 & 1 & 2 & 10274.694 & -0.108 \\
\hline 3 & 1 & 3 & 2 & 3 & 2 & 1 & 2 & 1 & 2 & 10274.856 & -0.133 \\
\hline 3 & 1 & 2 & 4 & 4 & 2 & 1 & 1 & 3 & 4 & 11991.333 & -0.018 \\
\hline 3 & 1 & 2 & 4 & 4 & 2 & 1 & 1 & 3 & 3 & 11991.478 & -0.048 \\
\hline 3 & 1 & 2 & 2 & 3 & 2 & 1 & 1 & 1 & 2 & 11991.572 & -0.041 \\
\hline 3 & 1 & 2 & 4 & 5 & 2 & 1 & 1 & 3 & 4 & 11991.599 & -0.020 \\
\hline 3 & 1 & 2 & 3 & 2 & 2 & 1 & 1 & 2 & 2 & 11991.934 & -0.086 \\
\hline 4 & 1 & 4 & 5 & 5 & 3 & 1 & 3 & 4 & 4 & 13637.214 & -0.010 \\
\hline 4 & 1 & 4 & 5 & 6 & 3 & 1 & 3 & 4 & 5 & 13637.264 & -0.003 \\
\hline 4 & 1 & 4 & 4 & 5 & 3 & 1 & 3 & 3 & 4 & 13637.365 & 0.045 \\
\hline 4 & 1 & 4 & 4 & 4 & 3 & 1 & 3 & 3 & 3 & 13637.308 & 0.053 \\
\hline 4 & 0 & 4 & 4 & 4 & 3 & 0 & 3 & 3 & 3 & 14321.510 & -0.041 \\
\hline
\end{tabular}

agreement between experimental and calculated rotational constants as confirmation that calculated double $\mathrm{H}$-bonded structures correctly represent the dominant gas-phase structure of the complex. The calculated hydrogen bond lengths of $1.83 \AA$ and $1.90 \AA$, shown in Table III, indicate a fairly strongly bound complex. The inertial defect calculated from the experimental rotational constants is $\Delta=-0.243 \mathrm{amu} \AA^{2}$, which is consistent with a planar structure. The small negative nonzero value of the inertial defect indicates the presence of out of plane vibrational modes within the molecule. ${ }^{26}$ The inertial defect for the tropolone-formic acid complex ${ }^{10}$ constants is $\Delta=-1.46$ amu $\AA^{2}$ and $\Delta=1.33$ amu $\AA^{2}$ for the propiolic acid-formic acid complex, ${ }^{4}$ and for $\mathrm{B}-\mathrm{N}$ naphthalene $\left({ }^{11} \mathrm{~B}^{14} \mathrm{~N}\right)$, $\Delta=-0.159 \mathrm{amu} \AA^{2} .27$ 
TABLE II. The experimental and calculated molecular parameters for the formamidinium formate complex in $\mathrm{MHz}$. Basis sets for the calculations are M11 with Def2-TZVPPD, B3LYP with aug-cc-pVQZ, MP2 with aug-cc-pVTZ, and PBE1PBE (synonymous with PBE0) with aug-cc-pVTZ, as described in the text. Further comparisons between theoretical and experimental data are shown in Table SM-1 of the supplementary material. For the experimental results, 34 transitions were included with a standard deviation of $4.6 \mathrm{kHz}$.

\begin{tabular}{lcccccc}
\hline \hline Parameter & Experimental & M11 & B3LYP(QZ) & B3LYP(TZ) & MP2(TZ) & PBE0 \\
\hline A & $5881.714(13)$ & 5792.09 & 5721.70 & 5712.89 & 5706.92 & 5758.06 \\
B & $2148.78635(17)$ & 2152.21 & 2134.43 & 2136.42 & 2154.46 & 2203.58 \\
C & $1575.20549(12)$ & 1569.15 & 1554.53 & 1554.93 & 1564.02 & 1593.69 \\
$1.5 \chi_{\text {aa }}(\mathrm{N} 1)$ & $1.6342(35)$ & 1.6894 & 1.9420 & 1.8246 & 0.98639 & 1.652 \\
$0.25\left(\chi_{\mathrm{bb}}-\chi_{\mathrm{cc}}\right)(\mathrm{N} 1)$ & $0.1594(36)$ & 1.4275 & 1.5421 & 1.5039 & -0.83887 & 1.440 \\
$\chi_{\mathrm{ab}}$ & & 0.19961 & 0.1602 & 0.13068 & -2.31404 & 0.139 \\
$1.5 \chi_{\mathrm{aa}}(\mathrm{N} 2)$ & $-1.5776(38)$ & -3.9571 & -3.6414 & -3.5030 & 1.4407 & -3.23 \\
$0.25\left(\chi_{\mathrm{bb}}-\chi_{\mathrm{cc}}\right)(\mathrm{N} 2)$ & $0.0197(19)$ & 0.3791 & 0.4730 & 0.4547 & 0.4830 & 0.48 \\
$\chi_{\mathrm{ab}}$ & & 0.1994 & 0.0594 & 0.0832 & -0.326 & 0.09 \\
$D_{\mathrm{J}}$ & $0.0023101(36)$ & & & & & \\
$\mu_{\mathrm{a}}(\mathrm{D})$ & & 3.343 & 3.285 & 3.288 & 3.195 & 3.409 \\
$\chi_{\text {aa }}(\mathrm{N} 1)$ & 1.0895 & 1.126 & 1.295 & & & \\
$\chi_{\mathrm{bb}}(\mathrm{N} 1)$ & -0.2260 & 2.292 & 2.437 & & & \\
$\chi_{\mathrm{cc}}(\mathrm{N} 1)$ & -0.8636 & -3.418 & -3.732 & & & \\
$\chi_{\text {aa }}(\mathrm{N} 2)$ & -1.0517 & -2.638 & -2.428 & & & \\
$\chi_{\mathrm{bb}}(\mathrm{N} 2)$ & 0.5653 & 2.077 & 2.160 & & & \\
$\chi_{\mathrm{cc}}(\mathrm{N} 2)$ & 0.4865 & 0.561 & 0.268 & & & \\
\hline \hline
\end{tabular}

TABLE III. Geometric parameters for hydrogen bonding in the x-ray structure. Bond lengths in $\AA$ and angle in degrees.

\begin{tabular}{lllll}
\hline \hline $\mathrm{D}-\mathrm{H} \cdots \mathrm{A}$ & $\mathrm{d}(\mathrm{D} \cdots \mathrm{A})$ & $\mathrm{d}(\mathrm{D}-\mathrm{H})$ & $\mathrm{d}(\mathrm{H} \cdots \mathrm{A})$ & $<(\mathrm{D}-\mathrm{H} \cdots \mathrm{A})$ \\
\hline $\mathrm{N}(2)-\mathrm{H}(2 \mathrm{~A}) \cdots \mathrm{O}(1)$ & $2.7982(10)$ & $0.973(11)$ & $1.825(11)$ & $178.5(12)$ \\
$\mathrm{N}(2)-\mathrm{H}(2 \mathrm{~B}) \cdots \mathrm{O}(1)$ & $2.8635(11)$ & $0.971(5)$ & $1.902(6)$ & $170.0(15)$ \\
\hline \hline
\end{tabular}

\section{Ab initio AND DENSITY FUNCTIONAL CALCULATIONS}

The molecular structure, rotational constants, and the quadrupole coupling at the two distinct ${ }^{14} \mathrm{~N}$ atoms were calculated for both formamidine and the doubly hydrogen bonded dimer by $a b$ initio and density functional calculations. The best agreements between measured and calculated rotational constants were obtained with DFT, M11 functional when combined with the Ahlrichs Group default 2nd series triple zeta valence basis set containing additional polarization functions (Def2-TZVPPD), as shown in Table IV. The TZVP is almost as good. The theoretical results obtained with other methods and functionals are given in Table II and Table SM-1 (supplementary material). Although the rotational constants from several of these calculations are acceptable when compared with the experimental microwave analysis, the calculated quadrupole coupling parameters differ greatly from the observations.

The primary software used in all calculations was the Gaussian09 and -16 suites (G-09 and G-16). ${ }^{28,29}$ These calculations were performed at both the Universities of Arizona and Edinburgh, as detailed in the Acknowledgments. An important aspect was the use of the keywords "output = pickett;" this provides microwave parameters, such as A, B, and C, as well as the electric field gradients (EFGs), which lead directly to the ${ }^{14} \mathrm{~N}$ quadrupole coupling values at the $\mathrm{N}$-atoms in the IA (inertial axis) axis system. These results are important to compare with the microwave determined values, also in the IA system. A variety of triple zeta valence basis sets were utilized in the search for agreement with experimental structural data. However, the difficulty in obtaining ${ }^{14} \mathrm{~N}$ quadrupole coupling results which were even close in comparison with the spectral data, meant that a number of other DFT methods available in G-09 and G-16 were tested, and none were really satisfactory.

The choice of which methods to select for equilibrium structure determination was based on the closeness of the calculated inertial axis rotational constants $\mathrm{A}, \mathrm{B}$, and $\mathrm{C}$ to the experimental values, together with values for the two measured quadrupole coupling parameters $\left[3 / 2^{*} \chi\right.$ aa and $\left.1 / 4^{*}(\chi b b-\chi c c)\right]$ being of correct sign.

The calculated dipole moments for $\mu_{\mathrm{a}}$ are relatively constant, with typical values for M11, MP2, and B3LYP being 3.34, 3.34, and $3.23 \mathrm{D}$, respectively. The values for $\mu_{\mathrm{b}}$ are more variable, but lower with values $0.18,0.28$, and $0.26 \mathrm{D}$ for these methods, respectively. 
TABLE IV. Comparison of the closest calculated results with experiments. The M11 functional with triple zeta basis sets was used for these calculations. Values are in $\mathrm{MHz}$.

\begin{tabular}{|c|c|c|c|c|c|c|c|}
\hline \multirow{2}{*}{$\frac{\text { Centre }}{{ }^{14} \mathrm{~N} \chi}$} & \multirow[b]{2}{*}{$\mathrm{A}$} & \multirow[b]{2}{*}{ B } & \multirow[b]{2}{*}{$\mathrm{C}$} & \multicolumn{2}{|c|}{ N1 } & \multicolumn{2}{|c|}{$\mathrm{N} 2$} \\
\hline & & & & $3 / 2^{*} x$ aa & $1 / 4^{*}(\chi b b-\chi c c)$ & $3 / 2^{*} x$ aa & $1 / 4^{*}(\chi b b-\chi c c)$ \\
\hline Expt. & 5881.714 & 2148.786 & 1575.205 & $1.6342(35)$ & $0.1594(36)$ & $-1.5776(38)$ & $0.0197(19)$ \\
\hline TZVP & 5792.09 & 2152.21 & 1569.15 & 1.7576 & 1.4985 & -3.8336 & 0.4595 \\
\hline Def2-TZVPPD & 5780.53 & 2141.76 & 1562.74 & 1.6894 & 1.4275 & -3.9192 & 0.4707 \\
\hline
\end{tabular}

As expected strong a-dipole transitions were observed, but no bdipole transitions were found. Some results of earlier calculations, including derived parameters are given in Table II and Table SM-1 (supplementary material). The list of acronyms for functionals used is shown in the G-09 and G-16 Manuals. ${ }^{28,29}$

\section{RESULTS AND DISCUSSION}

\section{A. The X-ray structure of formamidinium formate}

The structure consists of parallel layers when viewed along the b-axis (Fig. 2). Within each layer, there is a hydrogen-bonded network consisting of formamidinium and formate ions which each have standard molecular dimensions (Fig. 3). Both are symmetrical and perfectly planar. The dimensions of the formate ion are similar to those occurring in ammonium formate, ${ }^{30}$ while those of the formamidinium ion match well with those in the remarkable lanthanide complexes $\mathrm{HC}\left(\mathrm{NH}_{2}\right)_{2}{ }^{+} \mathrm{M}\left(\mathrm{HCO}_{2}\right)_{4}{ }^{-}(\mathrm{M}=\mathrm{Eu}, \mathrm{Gd}, \mathrm{Tb}, \mathrm{Dy}$, $\mathrm{Er}, \mathrm{Yb})$, where both formamidinium and formate ions are formed in situ by disproportionation of formamide in the hydrothermal synthesis. ${ }^{31}$ Within the layers, each formamidinium ion interacts with a formate ion by two $\mathrm{N}(2)-\mathrm{H}(2 \mathrm{~A})-\mathrm{O}(1)$ interactions and with two further formates each by one $\mathrm{N}(2)-\mathrm{H}(2 \mathrm{~B})-\mathrm{O}(1)$ interaction (Fig. 4). Likewise each formate ion interacts with a formamidinium by two $\mathrm{N}(2)-\mathrm{H}(2 \mathrm{~A})-\mathrm{O}(1)$ interactions and with two further formamidiniums each by one $\mathrm{N}(2)-\mathrm{H}(2 \mathrm{~B})-\mathrm{O}(1)$. The parameters for these two interactions (Table III) are well within the normal range for strong $\mathrm{NH}-\mathrm{O}$ hydrogen bonds, with the former being slightly stronger and more accurately linear. The orientation of ions

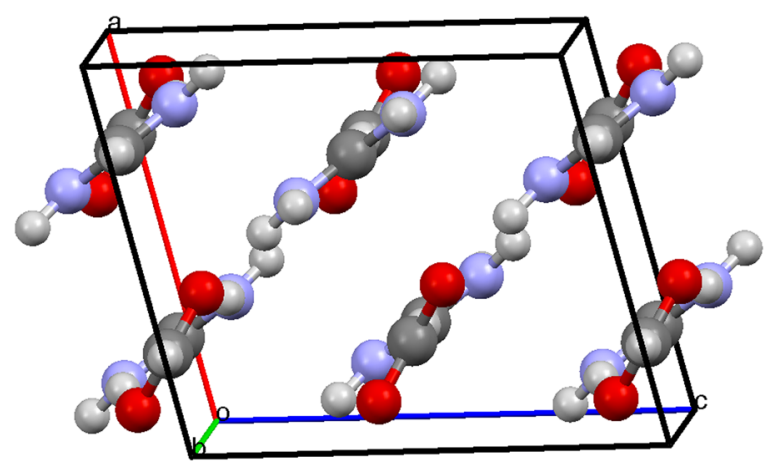

FIG. 2. Unit cell in the x-ray structure showing parallel planes of ions. within each layer is consistent but this is reversed in alternate layers resulting in an overall centrosymmetric structure.

Calculations also yielded a singly bonded structure very similar to the basic unit shown in Fig. 3, but without the additional hydrogen bonding present in the crystal lattice. This structure is $0.42 \mathrm{eV}$ higher in energy than the doubly H-bonded structure shown in Fig. 1. We see from Fig. 4 that hydrogen bonding to both $\mathrm{N}$ atoms in formamidine is present in both the gas-phase dimer and the crystal structure.

\section{B. The magnitude of ${ }^{1} \mathrm{~J}_{\mathrm{C}-\mathrm{H}}$ from ${ }^{13} \mathrm{C}$ NMR spectroscopy}

The magnitude of the one-bond spin-spin coupling constant between $\mathrm{C}$ and $\mathrm{H}$ observed by NMR spectroscopy is well known to give an indication of the state of hybridization at a given carbon atom, ${ }^{32}$ and more recent studies have focused on the angular dependence of the observed value ${ }^{33}$ as well as its use as a probe of stereoelectronic effects. ${ }^{34}$ A theoretical basis for the use of this parameter was established at an early stage, ${ }^{35}$ and a new method for direct determination of the value in complex molecules has been described recently. ${ }^{36}$ In the present case, the system is simple enough for direct measurement of the values simply by running the ${ }^{13} \mathrm{C}$ NMR spectrum without ${ }^{1} \mathrm{H}$ decoupling, and the results (Fig. 5) offer some insight into the structure of the formamidine/formic acid complex in solution. Using a solution in $\mathrm{d}_{6}$-dimethyl sulfoxide (DMSO), the values were readily determined to be $185.3 \mathrm{~Hz}$ for the $\mathrm{H}-\mathrm{C}(\mathrm{O})_{2}$ and $188.0 \mathrm{~Hz}$ for $\mathrm{H}-\mathrm{C}(\mathrm{N})_{2}$ (Fig. 5). Taking the formate value first, this can be compared to $221 \mathrm{~Hz}$ for formic acid, ${ }^{37} 226.2 \mathrm{~Hz}$ for methyl formate, and $225.6 \mathrm{~Hz}$ for ethyl formate, ${ }^{38}$ but $194.8 \mathrm{~Hz}$ for the formate anion in sodium formate in $\mathrm{D}_{2} \mathrm{O}{ }^{39}$ The value is thus indicative of ionic formate rather than formic acid in solution. Precedents for the formamidinium part are harder to find but the effects of stereochemistry ${ }^{40}$ and adjacent heteroatoms ${ }^{47}$ on the value of ${ }^{1} J_{\mathrm{C}-\mathrm{H}}$ for aldimines and aldoximes have been examined. The best precedents for an $\mathrm{sp}^{2} \mathrm{CH}$ joined to two nitrogens come from heterocyclic chemistry with values such as $208 \mathrm{~Hz}$ for both C-2 of imidazole and C-3 of 1,2,4-triazole, ${ }^{42} 202.7$ for C-2 of pyrimidine and 207.5 for C-2 of 1,3,5-triazine, ${ }^{43}$ and 207.1 for C-3 of 1,2,4-triazine. ${ }^{44}$ Our value for what is assumed to be the acyclic formamidinium ion is clearly well below these values but it appears to be generally the case that acyclic $\mathrm{CH}$ compounds joined to the same heteroatoms have lower one-bond coupling constants than cyclic analogs. For example while dimethylformamide (DMF) has a value of 196.2 for $\mathrm{H}-\mathrm{C}(\mathrm{O})$ (N), ${ }^{38}$ this compares with $234 \mathrm{~Hz}$ for C-2 of 1,3,4-oxadiazole. ${ }^{45} \mathrm{We}$ 

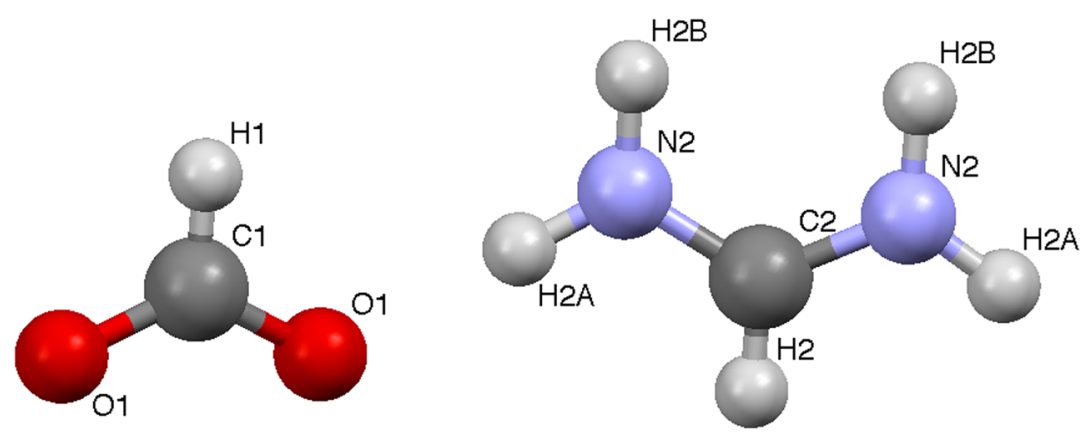

FIG. 3. The two ions present in the $x$-ray structure showing the numbering system used. Bond lengths and angles: $\mathrm{C}(1)-\mathrm{O}(1) 1.2464(9), \mathrm{C}(1)-\mathrm{H}(1) \mathrm{0.950}, \mathrm{C}(2)-\mathrm{N}(2)$ 1.3037(10), $\mathrm{C}(2)-\mathrm{H}(2) 0.950, \mathrm{~N}(2)-\mathrm{H}(2 \mathrm{~A})$ 0.973(5), N(2)-H(2B) 0.971(5) $\AA$; O(1)-C(1)-O(1) 127.41(13), O(1)-C(1)-H(1) 116.3, N(2)-C(2)-N(2) 124.39(12), $\mathrm{N}(2)-\mathrm{C}(2)-\mathrm{H}(2) 117.8, \mathrm{C}(2)-\mathrm{N}(2)-\mathrm{H}(2 \mathrm{~A}) 118.9(8), \mathrm{C}(2)-\mathrm{N}(2)-\mathrm{H}(2 \mathrm{~B}) 118.7(9), \mathrm{H}(2 \mathrm{~A})-\mathrm{N}(2)-\mathrm{H}(2 \mathrm{~B}) 121.6(13)^{\circ}$.

conclude from this measurement that, based on the comparison with sodium formate and formic acid, the compound exists in solution in a polar solvent such as DMSO mainly as fully ionic formamidinium formate. Determination of this parameter for a wider range of comparison compounds is, however, required to draw more reliable conclusions.

\section{Comparison of the calculated and microwave molecular parameters}

\section{The rotational constants}

A summary of the theoretical rotational constants (A, B, and C) and quadrupole parameters, which are closest to experiment values

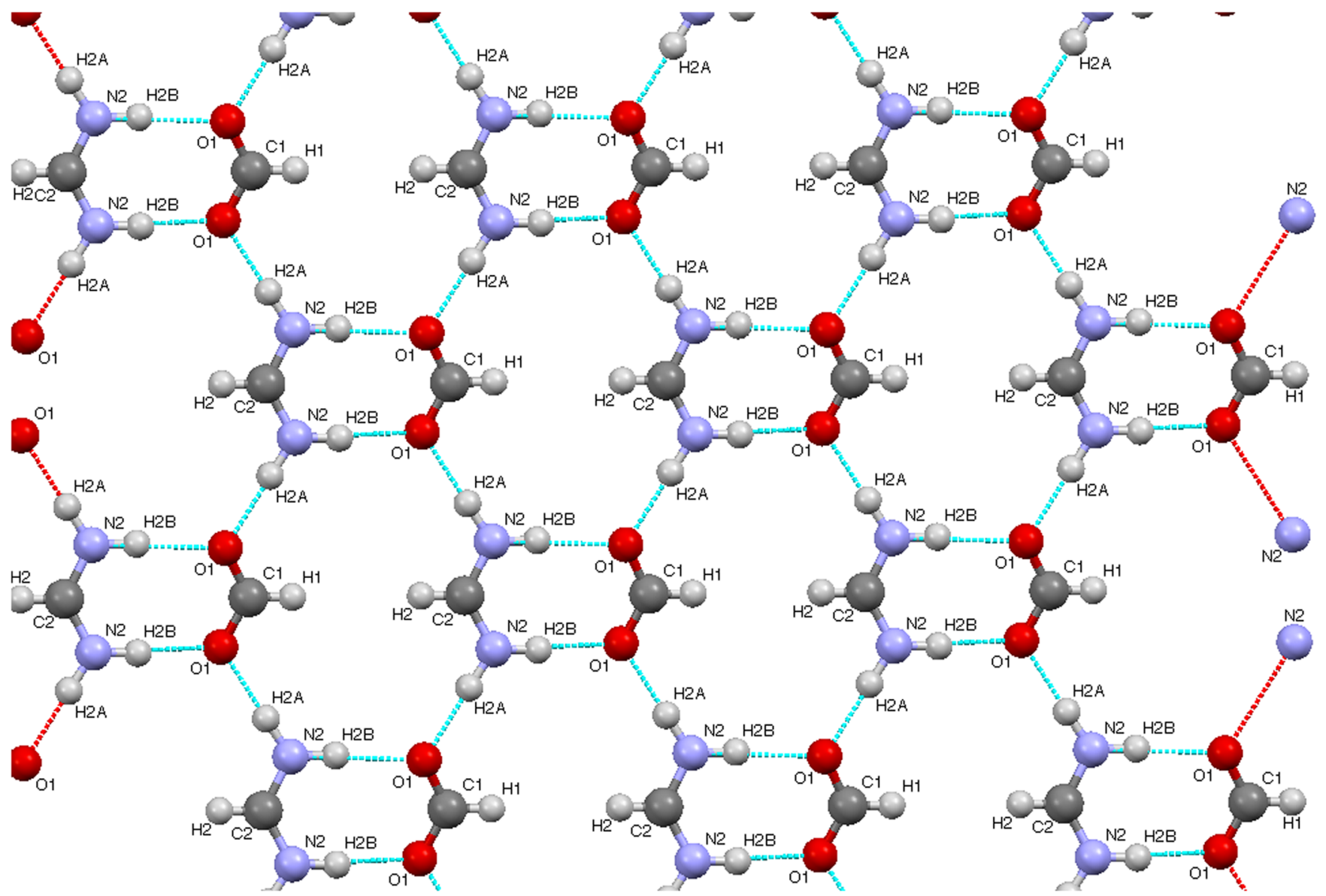

FIG. 4. Hydrogen bonded network within one layer. 


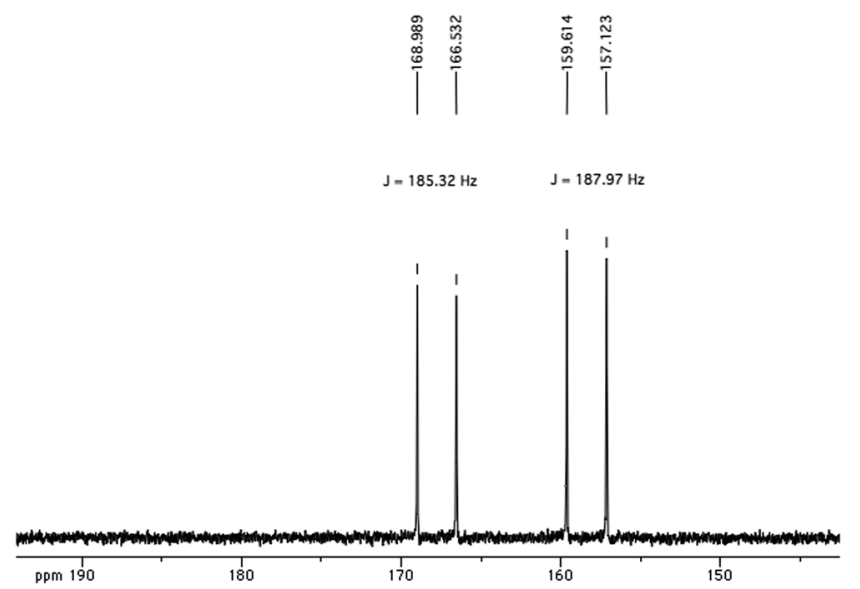

FIG. 5. Non-decoupled ${ }^{13} \mathrm{C}$ NMR spectrum $(75.458 \mathrm{MHz})$

for the dimeric structure, is shown in Table II, column 3. The overall closest values were obtained with the M11 functional ${ }^{46}$ with several triple zeta basis sets. ${ }^{47}$ The $\mathrm{A}, \mathrm{B}$, and $\mathrm{C}$ rotational constants based on the M11 functional when combined with the Def2-TZVPPD basis set are numerically closest to experiments with calculated/observed ratios of $98.3 \%, 99.6 \%$, and $99.1 \%$ for $\mathrm{A}, \mathrm{B}$, and C, respectively, and are shown in Table II, column 3. We believe that the calculated, equilibrium structure A, B, and C agrees well with experiments, even though the hydrogen bonding protons are exhibiting large amplitude motions because the moments of inertia are primarily influenced by the heavy atoms, farther from the center of mass of the complex. The hydrogen bonding protons are much lighter and very near the center of mass of the complex so, even though they exhibit large amplitude motions, that motion has very little effect on the moments of inertia.

\section{The quadrupole coupling parameters}

The calculated quadrupole coupling values are considerably different in both sign and magnitude from the measured values. This caused considerable difficulty in making initial assignments for the experimental spectra. The best theoretical values for the ${ }^{14} \mathrm{~N}$ quadrupole coupling constants, however, are only close to the observed values for $\chi_{\mathrm{aa}}$ at $\mathrm{N} 1$ and $\chi_{\mathrm{cc}}$ at N2. Several derived values are not even of the correct sign, especially $\chi_{\mathrm{bb}}$ at N1. This problem is discussed below and is thought to be a result of large amplitude motions of the hydrogen bonding protons, which have a very large effect on the quadrupole parameters (see Sec. IV F).

\section{Test calculations for the formamide-formic acid dimer}

In order to further test the theory that the quadrupole coupling difficulties are caused by the large amplitude vibrations of the protons, the same theoretical methods were used to calculate molecular parameters for the closely related formamide-formic acid dimer. ${ }^{6}$ For this complex, the present methods give very close agreement for BOTH the observed rotational constants and ${ }^{14} \mathrm{~N}$ quadrupole coupling parameters. For the formamide-formic acid dimer, the observed/theoretical values in $\mathrm{MHz}$ are $\mathrm{A}=5889.47 / 5976.45$,
$\mathrm{B}=2148.74 / 2158.64$, and $\mathrm{C}=1575.12 / 1585.84$ and ${ }^{14} \mathrm{~N}$ quadrupole coupling similarly as $\chi_{\mathrm{aa}}=1.014(5) / 1.0015, \chi_{\mathrm{bb}}=1.99(1) / 1.9229$, and $\chi_{\mathrm{cc}}=-3.00(1) /-2.9244$. This comparison clearly indicates that special features of the formamidinium formate complex, such as large amplitude motions, are very likely to be responsible for difficulties with $\chi$ values for the formamidine-formic acid cyclic dimer.

\section{The structure of the doubly hydrogen bonded dimer}

The structure based on the M11 density functional with the Def2-TZVPPD basis set, shown in Fig. 1, gives very close agreement with the observed gas phase rotational constants. The effectively planar dimer contains both the long $\mathrm{HN} \cdots \mathrm{H}-\mathrm{O}$ bond (1.611 $\AA$ ) between the imine lone pair orbital and an even longer $\mathrm{N}-\mathrm{H} \cdots \mathrm{O}$ =C bond $(1.887 \AA)$. It is clearly a double $\mathrm{H}$-bonded complex since the formate moiety has very different $\mathrm{C}-\mathrm{O}$ bonds, while the formamidine residue has unequal $\mathrm{C}-\mathrm{N}$ bonds. The study by Krechl et $a .^{21}$ reported a non-planar complex, with the same structural shape, but the dimer was calculated to be an electrostatic complex of ionized formamidinium and formate ions. Agranat et al. ${ }^{14}$ noted that all small basis set studies favored the combination of ions in the dimer over the covalent species. This is the state observed in the x-ray structure but is clearly incompatible with the gas-phase results. The Agranat et al. study ${ }^{14}$ led to a nonplanar $\mathrm{C}_{1}$ symmetry dimer, owing to pyramidal character of the $\mathrm{NH}_{2}$ group, with rather longer $\mathrm{N} \cdots \mathrm{H}(1.821 \AA)$ and $\mathrm{O} \cdots \mathrm{H}(2.049 \AA)$ distances than are found here. Kim et al. ${ }^{11}$ reported both transition state and energy minima for both the ionic and covalent states, but the solvent environment was the focus. At the $\mathrm{MP} 2$ level, their $\mathrm{N}-\mathrm{H} \cdots \mathrm{O}$ distance is $1.936 \AA$ and $\mathrm{O}-\mathrm{H} \cdots \mathrm{N}$ $1.636 \AA$; both are relatively similar to the present work. Simperler et $a l .{ }^{15}$ studied the sequence of events involving double proton transfer between two identical forms of the complex. Attempts to find a double proton-transfer transition state failed, and it was concluded that the overall process occurs by two consecutive proton transitions. Their complex at the MP2, B3P86, and B3LYP levels shows the difference in angles at the two $\mathrm{H}$-bonded centres, that is

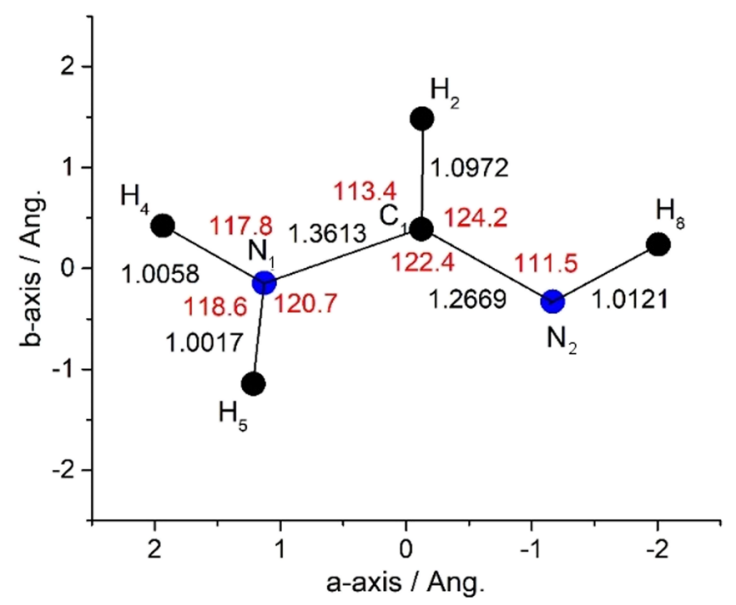

FIG. 6. Bond lengths and angles for formamidine in the inertial axis frame. The atomic numbering is the same as those of the dimer in Fig. 1. 
TABLE V. The M11 calculated rotational constants and ${ }^{14} \mathrm{~N}$ quadrupole coupling for the formamidine monomer, values are in $\mathrm{MHz}$.

\begin{tabular}{|c|c|c|c|c|c|c|c|c|c|}
\hline \multirow{2}{*}{$\frac{\text { Centre }}{{ }^{14} \mathrm{~N} \chi}$} & \multirow[b]{2}{*}{ A } & \multirow[b]{2}{*}{ B } & \multirow[b]{2}{*}{$\mathrm{C}$} & \multicolumn{3}{|c|}{ N1 } & \multicolumn{3}{|c|}{ N2 } \\
\hline & & & & $\chi^{\text {aa }}$ & $x \mathrm{bb}$ & $x \mathrm{cc}$ & $\chi^{\text {aa }}$ & $x \mathrm{bb}$ & $\chi c c$ \\
\hline M11 & 68755.74 & 10877.46 & 9391.66 & 2.2553 & 2.1433 & -4.3987 & 1.8300 & -3.5904 & 1.7604 \\
\hline
\end{tabular}

found here, with $\mathrm{N} \cdots \mathrm{H}-\mathrm{O}$ nearly linear, while $\mathrm{N}-\mathrm{H} \cdots \mathrm{O}=\mathrm{C}$ is bent to $165^{\circ}$.

\section{E. Comparison of the cyclic dimer structure with the separate molecules}

The theoretical structure for free formamidine, shown in Fig. 6, has a very similar structure to this moiety in the dimer in Fig. 1, where the same atomic numbering is used for both compounds. Two different out-of-plane distances for the two amino $\mathrm{H}$-atoms are also shown in Fig. 6. Thus the monomer has a small twist and is overall $\mathrm{C}_{1}$ symmetry. However, the in-plane inertial axes between the dimer and monomer (D and $\mathrm{M}$ ) are rotated by almost exactly $90^{\circ}$; this interchanges $\mathrm{a}$ and $\mathrm{b}$ axes between the two molecules and allows closer comparison. It is convenient at this point to consider the electric field gradient $(\mathrm{q})$ principal axes ( $\mathrm{xx}, \mathrm{yy}$, and $\mathrm{zz}$ ) as well as the inertial axis components; we adopt the common convention for these EFG-PA, $\left|\mathrm{q}_{z z}\right| \geq\left|\mathrm{q}_{\mathrm{yy}}\right| \geq\left|\mathrm{q}_{\mathrm{xx}}\right|$. The calculated rotational constants and ${ }^{14} \mathrm{~N}$ quadrupole coupling for the free formamidine monomer are given in Table $\mathrm{V}$.

We consider the out-of-plane terms at both $\mathrm{N}$-atom centers first since both are EFG-PA, and neither are directly involved in the H-bonding process. For the amino group centers $\left(\mathrm{N}_{3}\right.$ in both molecules), $\chi_{c c}$ are negative with calculated values $-5.138(\mathrm{M})$ and -3.418 (D) $\mathrm{MHz}$, respectively. The effect of H-bonding leads to a change in $\chi_{c c}$ of $+1.7 \mathrm{MHz}$. At the imine center's $\left(\mathrm{N}_{7}\right)$, the outof-plane terms, also EFG-PA, are the smallest $\left(\mathrm{q}_{\mathrm{xx}}\right)$. The values are $+1.4809(\mathrm{M})$ and +0.5608 (D) $\mathrm{MHz}$; the complex leads to a negative change in magnitude of $0.9 \mathrm{MHz}$. This implies a shift of electron density from the amino group towards the imine group on complex formation.

The EFG-PA of the classical lone pair of the imine is $-3.5247 \mathrm{MHz}(\mathrm{M})$ and lies in a similar position to $\chi_{\mathrm{aa}}$ of the dimer with $-2.64 \mathrm{MHz}(\mathrm{D})$. The difference is close to $1 \mathrm{MHz}$ and again implies that a loss of electron density at $\mathrm{N}_{7}$ occurs on complex formation. The other in-plane EFG-PA lies close to the external bisector of the $\mathrm{C}_{1} \mathrm{~N}_{7} \mathrm{H}_{6}$ angle for both molecules. The comparable values are $\chi_{\mathrm{yy}}+2.04 \mathrm{MHz}(\mathrm{M})$ and $\chi_{\mathrm{bb}}+2.0773 \mathrm{MHz}(\mathrm{D})$, with little change between the two molecules.

\section{F. Variation of the quadrupole coupling parameters as the $\mathrm{H}$-bonding distances are varied}

The above calculations account well for the rotational constants, and as a result the structure appears likely to be close to the true structure. However, the inability to account for the ${ }^{14} \mathrm{~N}$ quadrupole coupling in detail requires a more detailed analysis. We propose that the discrepancies between the experimental and calculated quadrupole coupling parameters are due to wide amplitude motions of the $\mathrm{H}$-bonding protons in the relatively flat potential
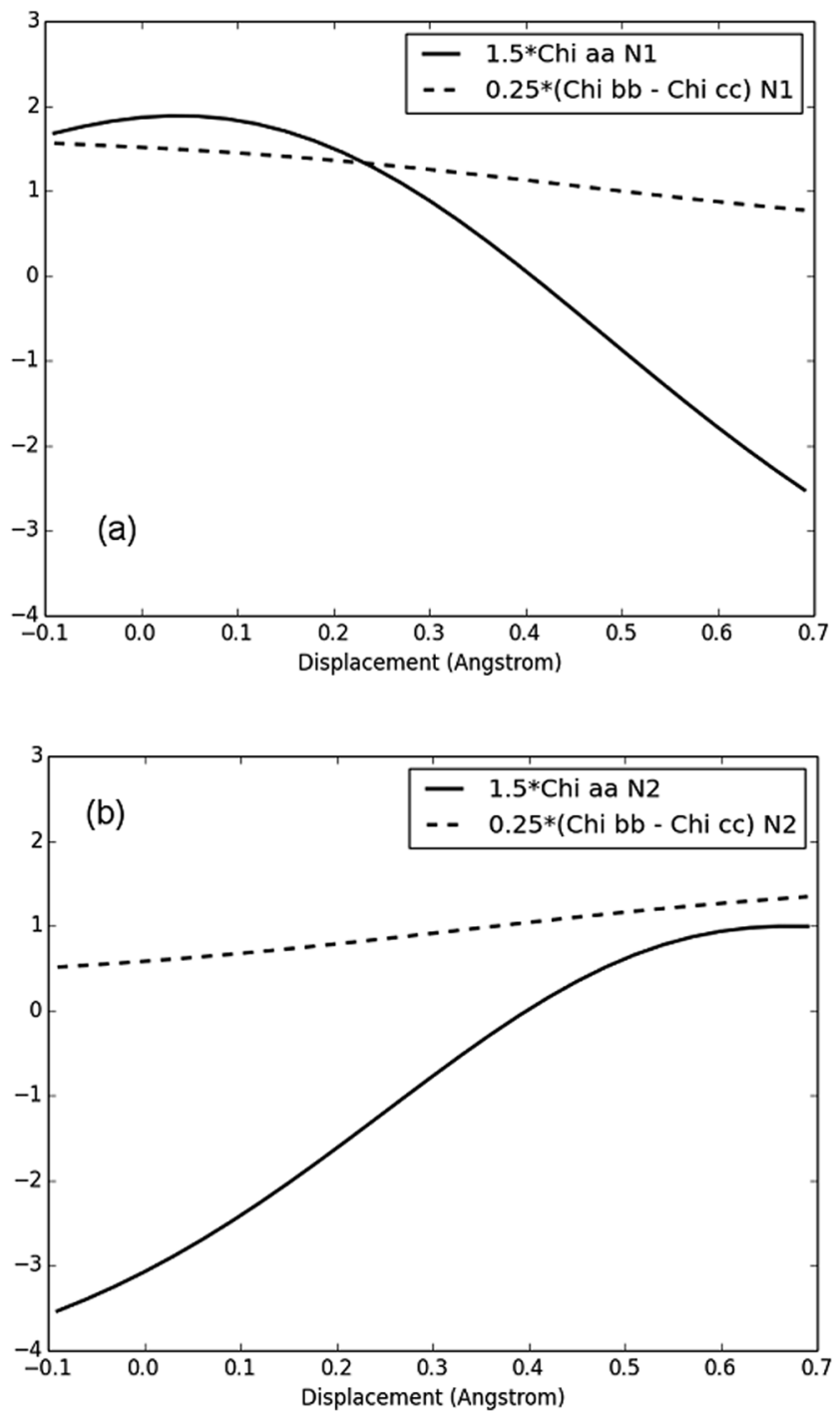

FIG. 7. Variation of the quadrupole parameters $1.5 \chi_{\mathrm{aa}}$ and $0.25\left(\chi_{\mathrm{bb}}-\chi_{\mathrm{cc}}\right)$ for $\mathrm{N} 1$ (a) and $\mathrm{N} 2$ (b) as the distance of the protons is varied in a concerted fashion from the equilibrium positions ( $\mathrm{y}$-axis is in $\mathrm{MHz}$ ) 


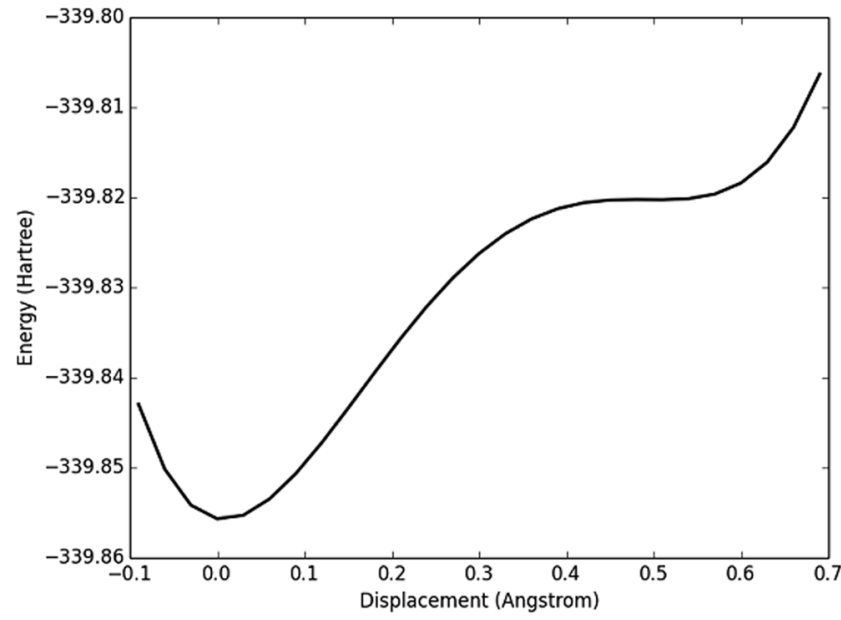

FIG. 8. Variation of the dimer energy as the distance of the protons is varied in a concerted fashion from the equilibrium positions.

between the $\mathrm{O}$ and $\mathrm{N}$ atoms. The above calculated $\mathrm{N} 1$ and $\mathrm{N} 2$ quadrupole parameters are for an equilibrium structure. In order to test this idea about the discrepancies, approximate calculations of the quadrupole parameters were performed for a range of $\mathrm{H}$ bonding proton locations. The quadrupole coupling parameters 1.5 $\chi_{\mathrm{aa}}$ and $0.25\left(\chi_{\mathrm{bb}}-\chi_{\mathrm{cc}}\right)$ were calculated, as the protons were moved in a concerted fashion from their optimized positions toward the other hydrogen bond acceptors with step displacements of $0.03 \AA .23$ steps were performed for this type of movement. These are only approximate calculations in Gaussian 09, B3LYP aug-cc-pVDZ, without optimization at each step. For each step, energy, rotational constants, and $\chi$ values were calculated. The quadrupole parameters for N1(a) and N2(b) are shown in Fig. 7. The energy profile is given in Fig. 8. If all atom coordinates were optimized for all steps, we would expect a more symmetrical energy profile.

Despite the lower level of calculation in this section, some important trends are shown in Fig. 7. (1) It is clear that there is a wide variation of the quadrupole coupling parameters $1.5 \chi_{\text {aa }}$ and $0.25\left(\chi_{\mathrm{bb}}-\chi_{\mathrm{cc}}\right)$ as the protons are moved toward the center between the $\mathrm{N}$ and $\mathrm{O}$ atoms, supporting the idea that the vibrational averaging for the experimental results will be significantly different from values calculated for the equilibrium structure. (2) The plots for N1 (a) and N2 (b) are near mirror images as would be expected since the assignments of $\mathrm{N} 1$ and $\mathrm{N} 2$ are expected to exchange at opposite ends of the tunneling pathway. (3) From Table II, the magnitudes of the calculated quadrupole parameters, $0.25\left(\chi_{b b}-\chi_{c c}\right)$ for N1 and1.5 $\chi_{\text {aa }}$ for $\mathrm{N} 1$, are larger than experimental ones and the plots in Fig. 7 indicate that these would be reduced with the vibrational averaging.

\section{CONCLUSIONS}

An efficient synthesis yielded pure samples of formamidinium formate which were studied using x-ray diffraction and Fourier transform microwave spectroscopy. The measured microwave spectra were accurately fit $(\sigma=5 \mathrm{kHz})$ using a rigid rotor Hamiltonian to obtain very accurate and precise rotational constants and quadrupole coupling parameters at both nitrogen atoms. Calculated rotational constants obtained using the best DFT and MP2 methods with triple-zeta basis sets agree with the experimental rotational constants with $1 \%-2 \%$ and better than $1 \%$ for the most favorable results. The lowest energy structure from these calculations is a double hydrogen bonded complex between formamidine and formic acid, as shown in Fig. 1. We interpret this agreement between calculated and measured structural parameters (the rotational constants) as convincing evidence that this is the correct structure for the gas phase complex. The solidstate, $\mathrm{x}$-ray structure shows an indication of double H-bonding between the formamidine and formic acid and shows this internal hydrogen bonding and external $\mathrm{H}$-bonding to surrounding molecules.

The calculated quadrupole coupling strengths for the lowest energy equilibrium geometry of the complex do not agree well with the measured values. We interpret this as strong evidence for large amplitude vibrational motions of the protons involved in the hydrogen bonding. There are quite large changes in the nitrogen quadrupole coupling strengths, as shown in Fig. 7, so the wide amplitude, vibrationally averaged values are likely to be different from the calculated equilibrium values. The hydrogen-bonding protons are light and fairly close to the center of mass of the complex, so this large amplitude motion would be expected to have a much smaller influence on the calculated rotational constants than on the quadrupole coupling parameters. With this flat potential for moving these protons and large amplitude motion, tunneling splittings may be expected, but tunneling splittings were not observed in the present work. Assigning these tunneling splittings in the presence of the complex nitrogen hyperfine structure would be difficult. This assignment of the problems with quadrupole coupling calculations to the wide amplitude vibrational motions of the protons is supported by test calculations on the more rigid formamide-formic acid complex, where very good agreement between experimental and calculated quadrupole coupling parameters was obtained. It is also supported by calculations showing large changes in quadrupole coupling strengths as the hydrogen bonding protons are moved along tunneling pathways. Better calculations for formamidinium formate will require generating a potential surface, followed by careful dynamics calculations. ${ }^{48}$

\section{SUPPLEMENTARY MATERIAL}

See supplementary material for Table SM-1 for the results of other calculation testing MP2, MP3, and DFT with various basis sets. Whereas the rotational constants are fairly consistent, the quadrupole coupling results are not very consistent between the various calculations.

\section{ACKNOWLEDGMENTS}

This material is based upon work supported by the National Science Foundation under Grant No. CHE-1057796 at the University of Arizona. M.H.P. wishes to acknowledge the support of the Edinburgh Parallel Computing Centre (EPCC) for access to the Cirrus computer. We thank Professor Dennis Lichtenberger for providing help and instruction for $\mathrm{H}$. Wang in his computational chemistry course. 


\section{REFERENCES}

${ }^{1}$ F. Madeja and M. Havenith, J. Chem. Phys. 117, 7162-7168 (2002); A. Gutberlet, G. W. Schwaab, and M. Havenith, Chem. Phys. 343, 158-167 (2008); Ö. Birer and M. Havenith, Ann. Rev. Phys. Chem. 60, 263-275 (2009).

${ }^{2}$ A. M. Daly, P. R. Bunker, and S. G. Kukolich, J. Chem. Phys. 132, 201101-1201101-3 (2010).

${ }^{3}$ A. M. Daly, P. R. Bunker, and S. G. Kukolich, J. Chem. Phys. 133, 079903-1 (2010).

${ }^{4}$ A. M. Daly, K. O. Douglass, L. C. Sarkozy, J. L. Neill, M. T. Muckle, D. P. Zaleski, B. H. Pate, and S. G. Kukolich, J. Chem. Phys. 135, 154304-1-154304-12 (2011). ${ }^{5}$ M. C. D. Tayler, B. Ouyang, and B. J. Howard, J. Chem. Phys. 134, 054316-1054316-9 (2011)

${ }^{6}$ A. M. Daly, B. A. Sargus, and S. G. Kukolich, J. Chem. Phys. 133, 174304-1174304-6 (2010).

${ }^{7}$ A. M Pejlovas, M. Barfield, and S. G. Kukolich, Chem. Phys. Lett. 613, 86-89 (2014).

${ }^{8}$ A. M. Pejlovas, W. Lin, and S. G. Kukolich, J. Chem. Phys. 143, 124311-1124311-6 (2015)

${ }^{9}$ A. M. Pejlovas and S. G. Kukolich, J. Mol. Spectrosc. 321, 1-4 (2016).

${ }^{10}$ A. M. Pejlovas, A. Serrato III, W. Lin, and S. G. Kukolich, J. Chem. Phys. 144, 044306-1-044306-3 (2016).

${ }^{11}$ Y. Kim, S. Lim, and Y. Kim, J. Phys. Chem. A 103, 6632-6637 (1999).

${ }^{12}$ J.-H. Lim, E. K. Lee, and Y. Kim, J. Phys. Chem. A 101, 2233-2239 (1997).

${ }^{13}$ K. Park, Y. Kim, K. H. Kim, and Y. Kim, Bull. Korean Chem. Soc. 32, 3634-3640 (2011).

${ }^{14}$ I. Agranat, N. V. Riggs, and L. Radom, J. Chem. Soc., Chem. Commun. 1991, $80-81$.

${ }^{15}$ A. Simperler, W. Mikenda, and K. Schwarz, Chem. Eur. J. 7, 1606-1613 (2001).

${ }^{16}$ J. Rebek, Science 235, 1478-1484 (1987), stable/1699046; M. Tintelnot and P. Andrews, J. Comput.-Aided Mol. Des. 3, 67-84 (1989).

${ }^{17}$ D. M. Salunke and M. Vijayan, Int. J. Peptide Protein Res. 18, 348-351 (1981).

${ }^{18}$ Y. Yokomori and D. J. Hodgson, Int. J. Peptide Protein Res. 31, 289 (1988).

${ }^{19}$ W. Gordy and R. L. Cook, Microwave Molecular Spectra (Wiley-Interscience, New York, 1984).

${ }^{20}$ E. G. Gemrich, B. L. Lee, M. L. Tripp, and E. Van de Streek, J. Econ. Entomol. 69, 301-306 (1976).

${ }^{21}$ J. Krechl, S. Böhm, S. Smrckova, and J. Kuthan, Collect. Czech. Chem. Commun. 54, 673-683 (1989).

${ }^{22} \mathrm{~N}$. Kihara, T. Mukaiyama, T. Ishitoku, and T. Katsuya, European patent 0259184 A1 (1988).

${ }^{23}$ R. E. Bumgarner and S. G. Kukolich, J. Chem. Phys. 86, 1083-1089 (1987).

${ }^{24}$ B. S. Tackett, C. Karunatilaka, A. M. Daly, and S. G. Kukolich, Organometallics 26, 2070-2076 (2007).

${ }^{25}$ H. M. Pickett, J. Mol. Spectrosc. 148, 371-377 (1991), http://spec.jpl.nasa. gov/ftp/pub/calpgm/spinv.html.

${ }^{26}$ T. Oka, J. Mol. Struct. 352-353, 225-233 (1995).
${ }^{27}$ A. M. Pejlovas, A. M. Daly, A. J. Ashe III, and S. G. Kukolich, J. Chem. Phys. 144, 114303-1-114303-10 (2016).

${ }^{28}$ M. J. Frisch, G. W. Trucks, H. B. Schlegel, G. E. Scuseria, M. A. Robb, J. R. Cheeseman, G. Scalmani, V. Barone, B. Mennucci, G. A. Petersson, et al. Gaussian 09, Revision A.1, Gaussian, Inc., Wallingford, CT, 2009.

${ }^{29}$ M. J. Frisch, G. W. Trucks, H. B. Schlegel, G. E. Scuseria, M. A. Robb, J. R. Cheeseman, G. Scalmani, V. Barone, G. A. Petersson, H. Nakatsuji, X. Li, M. Caricato, A. V. Marenich, J. Bloino, B. G. Janesko, R. Gomperts, B. Mennucci, H. P. Hratchian, J. V. Ortiz, A. F. Izmaylov, J. L. Sonnenberg, D. Williams-Young, F. Ding, F. Lipparini, F. Egidi, J. Goings, B. Peng, A. Petrone, T. Henderson, D. Ranasinghe, V. G. Zakrzewski, J. Gao, N. Rega, G. Zheng, W. Liang, M. Hada, M. Ehara, K. Toyota, R. Fukuda, J. Hasegawa, M. Ishida, T. Nakajima, Y. Honda, O. Kitao, H. Nakai, T. Vreven, K. Throssell, J. A. Montgomery, Jr., J. E. Peralta, F. Ogliaro, M. J. Bearpark, J. J. Heyd, E. N. Brothers, K. N. Kudin, V. N. Staroverov, T. A. Keith, R. Kobayashi, J. Normand, K. Raghavachari, A. P. Rendell, J. C. Burant, S. S. Iyengar, J. Tomasi, M. Cossi, J. M. Millam, M. Klene, C. Adamo, R. Cammi, J. W. Ochterski, R. L. Martin, K. Morokuma, O. Farkas,J. B. Foresman, and D. J. Fox, GAussian 16, Revision A.03, Gaussian, Inc., Wallingford, CT, 2016.

${ }^{30}$ I. Nahringbauer, Acta Crystallogr., Sect. B 24, 565-570 (1968).

${ }^{31}$ X. Ma, J. Tian, H.-Y. Yang, K. Zhao, and X. Li, J. Solid State Chem. 201, 172-177 (2013).

${ }^{32}$ P. E. Hansen, Prog. NMR Spectrosc. 14, 175-295 (1982).

${ }^{33}$ R. H. Contreras and J. E. Peralta, Prog. NMR Spectrosc. 37, 321-425 (2000).

${ }^{34}$ E. Juaristi and G. Cuevas, Acc. Chem. Res. 40, 961-970 (2007).

${ }^{35}$ G. E. Maciel, J. W. McIver, N. S. Ostlund, and J. A. Pople, J. Am. Chem. Soc. 92, 1-11 (1970).

${ }^{36}$ N. Marco, A. A. Souza, P. Nolis, C. Cobas, R. R. Gil, and T. Parella, J. Org. Chem. 82, 2040-2044 (2017)

${ }^{37}$ R. Fu and G. Bodenhausen, J. Magn. Reson., Ser. A 117, 324-325 (1995).

${ }^{38}$ E. R. Malinowski, L. Z. Pollara, and J. P. Larmann, J. Am. Chem. Soc. 84, 26492650 (1962).

${ }^{39}$ R. M. Hammaker, J. Mol. Spectrosc. 15, 506-508 (1965).

${ }^{40}$ R. R. Fraser and M. Bresse, Can. J. Chem. 61, 576-578 (1983).

${ }^{41}$ N. De Kimpe, R. Verhé, L. De Buyck, and N. Schamp, Can. J. Chem. 62, $1812-$ 1816 (1984).

${ }^{42}$ F. J. Weigert and J. D. Roberts, J. Am. Chem. Soc. 90, 3543-3549 (1968).

${ }^{43}$ F. J. Weigert, J. Husar, and J. D. Roberts, J. Org. Chem. 38, 1313-1316 (1973).

${ }^{44}$ S. Braun and G. Frey, Org. Magn. Reson. 7, 194-198 (1975).

${ }^{45}$ K. M. Aitken and R. A. Aitken, Arkivoc 2012(v), 75-79.

${ }^{46}$ R. Peverati and D. G. Truhlar, J. Phys. Chem. Lett. 2, 2810-2817 (2011).

${ }^{47}$ R. A. Kendall, T. H. Dunning, Jr., and R. J. Harrison, J. Chem. Phys. 96, 6796-6806 (1992); D. E. Woon and T. H. Dunning, Jr., ibid. 98, 1358-1371 (1993); F. Weigend and R. Ahlrichs, Phys. Chem. Chem. Phys. 7, 3297-3305 (2005); F. Weigend, ibid. 8, 1057-1065 (2006); A. Hellweg and D. Rappoport, ibid. 17, 1010-1017 (2015); D. Rappoport and F. Furche, J. Chem. Phys. 133, 134105-1-134105-11 (2010).

${ }^{48}$ C. Qu and J. M. Bowman, J. Phys. Chem. Lett. 9, 2604-2610 (2018). 